\title{
Numerical Taxonomy of Bacillus Isolates from North Sea Sediments
}

\author{
A. BOEYÉ AND M. AERTS \\ Laboratory of Microbiology and Hygiene, Vrije Universiteit Brussel, 1640 St. Genesius-Rode, Belgium
}

\begin{abstract}
A numerical taxonomic study of 138 Bacillus strains isolated from North Sea sediments is presented. The clustering process, based on 63 selected multistate features, resulted in the formation of two clusters separated by the VogesProskauer reaction. Further subdivision yielded six phenons, one of which corresponded to the conventional species Bacillus licheniformis. The strains, taken in the order in which they appeared in the dendrogram, exhibited a gradient in the frequency of positive answers to biochemical and physiological tests.
\end{abstract}

In exploratory studies of the aerobic, heterotrophic bacteria from the North Sea floor, a high proportion of the random isolates were identified as Bacillus strains (4). Since most attempts at conventional identification of these strains at the species level failed, a numerical taxonomic study was made, the results of which are presented in this paper. A balanced set of morphological, physiological, and biochemical tests was gradually elaborated, and the Adansonian principle of the equal weight of all features was used as a guide in the interpretation of results. The principle forbids repeating questions even in a different form. Redundancy was avoided by elimination of grossly correlated tests and by disregarding all test results predictable from a prior test.

While this work was in progress, a comprehensive numerical taxonomic study by Bonde $(5,6)$ came to our attention; it will be shown that our results, though based on an independent set of tests, in part confirm those of Bonde.

\section{MATERIALS AND METHODS}

\section{Isolation of Strains}

Sediment samples. All samples were collected in the North Sea off the Belgian and Dutch coasts over the period of January 1972 to April 1975. The limits of the collection area and the sampling and preservation methods were described elsewhere (4).

Isolation procedure. Serial dilutions of the sediment samples were plated on ZoBell marine agar (MA [25]). Colonies of all different types were picked out after 2 to 10 days of incubation at 18 or $30^{\circ} \mathrm{C}$. All isolates were purified three times by streaking on MA. Nonsporulating and apparent repeat isolates were discarded after examining the colonies and the results of Gram and spore staining.

Nineteen sediment samples were used in total. Each sample yielded from 2 to 18 different isolates. The strains are listed in Table 1.

\section{Identification at Species Level}

Reference strains. All reference strains used in this work are listed in Table 2. They include one representative each of 12 species (serial no. 1-12) which were encountered in attempts at identifying our own isolates.

Determinative keys. The two keys of Gordon (12) were used jointly. Preliminary tests using reference strains have shown that the results of this identification procedure were correct if, and only if, both keys assigned the strain to the same species.

The keys were used with a single modification, ignoring classification as Bacillus stearothermophilus based upon "growth at $65^{\circ} \mathrm{C}$." Since our strains were isolated at a temperature $\left(18\right.$ or $\left.30^{\circ} \mathrm{C}\right)$ at which all $B$. stearothermophilus strains fail to grow (12; it was verified that the three representative strains of this species listed in Table 2 failed to grow at temperatures up to and including $37^{\circ} \mathrm{C}$ ), none of our isolates, even when able to grow at $65^{\circ} \mathrm{C}$, could possibly belong to that species.

When one of the keys failed to yield a name or the two names were different, the strain was considered unidentifiable. A careful comparison with the description of the most relevant species in all cases confirmed the presence of unresolvable ambiguities.

\section{Test Procedures}

General. Unless specified otherwise, all tests were carried out at $30^{\circ} \mathrm{C}$. Published procedures were followed except for the determination of colonial morphology and sugar fermentation tests (see below). The analysis of only three out of 141 isolates had to be discontinued for lack of growth on most test media. Only one isolate (VUB 83) had an absolute requirement for salt. For this strain, $3.5 \% \mathrm{NaCl}$ was added to all media, except gelatin and litmus milk, which were altered by this addition.

Colonial morphology. Normal streak inoculation yields colonies whose size depends on their local density. In turn, other colonial features appear to depend on size. These uncertainties were avoided by implanting widely separated duplicate colonies by a 
touch of the inoculation needle and by reading the results after a long incubation time. Using marine agar and 10 days of incubation at $30^{\circ} \mathrm{C}$, highly reproducible readings of size, brilliance, opacity, and color intensity were obtained (color itself was not

TABLE 1. List of 138 new Bacillus strains isolated from North Sea sediments

\begin{tabular}{crl}
\hline $\begin{array}{c}\text { Sediment sam- } \\
\text { ple no. }\end{array}$ & $\begin{array}{c}\text { No. of iso- } \\
\text { lates }\end{array}$ & \multicolumn{1}{c}{ Designation } \\
\hline 1 & 4 & VUB 1-4 \\
2 & 4 & VUB 10-13 \\
3 & 2 & VUB 20-21 \\
4 & 10 & VUB 30-39 \\
5 & 2 & VUB 40-41 \\
6 & 14 & VUB 51-53, 55-56 \\
7 & 9 & VUB 70-78 \\
8 & 10 & VUB 80-89 \\
9 & 10 & VUB 120-129 \\
10 & 3 & VUB 130-132 \\
11 & 11 & VUB 140-150 \\
12 & 4 & VUB 160-163 \\
13 & 9 & VUB 170-175, 177-179 \\
14 & 2 & VUB 180-181 \\
15 & 7 & VUB 190-196 \\
16 & 8 & VUB 200-207 \\
17 & 18 & VUB 210-219, 221-226, 228- \\
& & 229 \\
18 & 6 & VUB 230-234, 236 \\
19 & 5 & VUB 251-252, 254-256
\end{tabular}

encoded since intensely colored strains were invariably orange).

Sugar fermentation tests. Using ammonium phosphate as the nitrogen source, very few positive results were obtained for the production of acid from 12 sugars (see below) other than glucose. A group of 19 strains yielded only $4 \%$ of positive results (eight positives in 228 tests). The information content of these tests was evidently very low due to the rarity of positive results. When peptone was used as the source of nitrogen, the same strains yielded $36 \%$ of positive results $(82 / 228)$, and the distribution was therefore much closer to the ideal fifty-fifty. For this reason, the acid production from all sugars was tested with peptone as the nitrogen source. The results were read daily for 5 days. Where eventual alkalinization of the medium occurred, it developed so slowly that the observation of the initial acidification was usually not interfered with. If the test was positive at any time within the 5 days, it was recorded as positive.

The acid production tests with ammonium nitrogen were dropped except for glucose. For this sugar, the distribution of positive and negative strains was better balanced ( 62 positive strains out of 138) with ammonium phosphate than with peptone (120 positives out of 138).

\section{Selected Tests}

The following 63 tests were used in the computation of the similarity coefficients. The number, $n$, of

TABLE 2. Collection strains used in this study

\begin{tabular}{|c|c|c|c|}
\hline \multirow{2}{*}{$\begin{array}{c}\text { Serial } \\
\text { no. }\end{array}$} & \multicolumn{2}{|c|}{ Received as: } & \multirow{2}{*}{ Status of phenetic group represented } \\
\hline & Collection no. ${ }^{a}$ & Name & \\
\hline 1 & CIP 5267 (=ATCC 7061) & Bacillus pumilus & Type strain \\
\hline 2 & CIP 5271 (=ATCC 14580) & B. licheniformis & Proposed neotype \\
\hline 3 & CIP $5265(=$ ATCC 6051$)$ & B. subtilis & Type strain \\
\hline 4 & CIP 5269 (=ATCC 8247) & B. firmus & \\
\hline 5 & CIP 5117 & B. megaterium & \\
\hline 6 & CIP A30 & B. cereus & \\
\hline 7 & CIP 5259 & B. cereus var. mycoides & \\
\hline 8 & CIP A3 & B. anthracis & \\
\hline 9 & CIP 5122 & B. brevis & \\
\hline 10 & CIP 5125 & B. sphaericus & \\
\hline 11 & CIP $5263(=$ ATCC 10545) & $B$. coagulans & \\
\hline 12 & CIP $5124(=$ ATCC 14576) & B. pantothenticus & \\
\hline 13 & IHA 53 & Unclassified & Phenon I (7) \\
\hline 14 & IHA 219 & B. pulvifaciens & Phenon IIA (7) \\
\hline 15 & IHA 448 & B. subtilis & Phenon IIAT (7) \\
\hline 16 & IHA 187 & Unclassified & Phenon IIB (7) \\
\hline 17 & IHA 24 & $B$. cereus & Phenon IIC (7) \\
\hline 18 & IHA 47 & B. subtilis & Phenon IIIA (7) \\
\hline 19 & IHA 321 & B. polymyxa & Phenon IIIB (7) \\
\hline 20 & IHA 280 & $B$. subtilis & Phenon IVA (7) \\
\hline 21 & IHA 43 & B. licheniformis & Phenon IVB (7) \\
\hline 22 & IHA 60 & B. licheniformis & Phenon V (7) \\
\hline 23 & $\mathrm{~T} 39$ & B. stearothermophilus & Physiol. group 1a (22) \\
\hline 24 & $\mathrm{~T} 136$ & B. stearothermophilus & Physiol. group 2 (22) \\
\hline 25 & $\mathrm{~T} 124$ & B. stearothermophilus & Physiol. group 3a (22) \\
\hline
\end{tabular}

a CIP, Collection of the Institut Pasteur, Paris, France; IHA, collection of the Institute of Hygiene, University of Aarhus, Aarhus, Denmark; T, kindly provided by J. Wolf, Department of Bacteriology, University of Leeds, Leeds, England. 
states of each character is given in parentheses. For $n \geq 3$, the meaning of the different states is explained when not immediately obvious. The sign $\S$ means that the character was also used in the computation of the positivity index.

Morphology of vegetative cells. Nutrient broth (NB) culture was used unless specified otherwise. Length (seven states, class boundaries 9, 7.5, 6, 4.5, 3 , and $1.5 \mu \mathrm{m}$ ) and width (seven states, class boundaries $1.5,1.3,1.1,0.9,0.7$, and $0.5 \mu \mathrm{m}$ ): average of 10 cells as measured from photograph of young culture. Chains (three states): presence of chains of at least four cells. Ghosts (two states): presence in old cultures. $\S$ Lipid droplets (two states): presence in the cytoplasm of cells grown on glucose agar and stained after Burdon (9). § Motility (combined results, three states): stab inoculation in $0.5 \%$ agar $(10, \mathrm{p}$. 292), and phase-contrast observation of young NB culture in hanging droplet. Flagella: silver impregnation (two states [21]). This test was done only with the strains that scored negative for one or both motility tests. The result was considered negative only if no flagella were observed in three independent preparations (Bacillus anthracis CIP A3 served as a negative control).

Spores and sporangia. Morphological characters were determined using cells from colonies on MA. Length (three states, class boundaries 3 and $1.5 \mu \mathrm{m}$ ) of sporangium: average length of 10 sporangia as measured from photograph. Sporangia clavate and/ or thick-walled (combined results, three states). Chains (three states): presence of chains of at least four sporangia. Abundance of sporulation (three states, class boundaries 80 and $10 \%$ ): percentage of spores and sporangia in 10-day-old NB culture. Heat resistance (three states): presence of viable spores in loopful after heating for $20 \mathrm{~min}$ in $\mathrm{NB}$ either at 80 or at $100^{\circ} \mathrm{C}$.

Colonial morphology. Observation of two wellseparated colonies (implanted by touch of inoculation needle) on MA after 10 days at $30^{\circ} \mathrm{C}$. $\S$ Average diameter (four states, class boundaries 12,6 , and 2 $\mathrm{mm}$ ), entirety of margin (two states), opacity (three states), § intensity of pigmentation (three states), brilliance (two states).

Growth in liquid medium. NB tube cultures at $30^{\circ} \mathrm{C}$ unless specified otherwise. Formation of pellicle (two states). Influence of $3.5 \% \mathrm{NaCl}$ (three states: positive, not detectable, negative) on growth at $30^{\circ} \mathrm{C} . \S \mathrm{NaCl}$ tolerance (seven states: $25,20,15$, $10,7,3.5,2$, and $0 \% \mathrm{NaCl}$ tolerated): highest $\mathrm{NaCl}$ concentration allowing visible growth in 7 days at $30^{\circ} \mathrm{C}$. $\S$ Temperature tolerance (seven states: 70,65 , $57,50,44,37$, and $30^{\circ} \mathrm{C}$ tolerated): highest temperature allowing visible growth in NB in 7 days (static incubation in water bath). § Acid tolerance: visible growth at $\mathrm{pH} 5.7\left(2\right.$ states) at $30^{\circ} \mathrm{C}$ in 5 days. $\S$ Growth at pH $6.0,60^{\circ} \mathrm{C}$ (two states [24]). Anaerobic growth in $\S$ glucose broth (NB with $0.5 \%$ glucose; tubes sealed with paraffin) and/or in HughLeifson medium ([1] combined results, three states).

Substrate utilization and modification. § Citrate utilization (two states): alkalinization of Simmons citrate. § Fumarate utilization: alkalinization of Koser medium (two states [15]) supplemented with $0.2 \%$ sodium fumarate and $1.5 \%$ agar. $\S$ Litmus milk coagulation in 28 days (three states: coagulation spontaneous, occurs only after short heating at $100^{\circ} \mathrm{C}$, none).

Enzymatic activities and products (other than acid). $\S$ Liquefaction of gelatin in 14 days at $18^{\circ} \mathrm{C}$ (two states [20, p. 55]). $\S$ Digestion of casein (two states $[10$, p. 498$]$ ), $\S$ starch (two states $[10$, p. 498]), $\S$ pectate (two states [14]), and $\S$ chitin (two states [23]). Hydrolysis of $\S$ egg-yolk lecithin (two states [10, p. 499], of $\S$ Tween 80 (two states [7]), of $\S$ esculin (two states $[8$, p. 60]). $\S$ Catalase: gas produced by bacterial paste in contact with $10 \%$ (wt/vol) $\mathrm{H}_{2} \mathrm{O}_{2}$ (three states [2, p. 260]). \& Oxidase: tetramethyl-pphenylene diamine oxidized (three states $[2, \mathrm{p}$. 261]). \& Urease: urea agar alkalinized (two states $[16$, p. 277]). Reduction of $\S$ nitrate (two states [2, p. $262])$, of $\S$ nitrite $\left(0.01 \% \mathrm{KNO}_{2}\right.$ in NB reduced in 10 days; two states). § Voges-Proskauer test: acetoin produced in 5 days at $30^{\circ} \mathrm{C}$ in Clark-Lubs medium, tested with $5 \% \alpha$-naphthol and $40 \% \mathrm{KOH}$ (two states [2, p. 260]). § Production of hydrogen sulfide (two states [10, p. 294]).

Fermentation of glucids. $\S$ Methyl red test (two states [2, p. 259-262]). § Hugh-Leifson test: anaerobic acidification (two states [1]). $\S$ Acid production from glucose using ammonium salts as the nitrogen source ( 2 states [22, p. 54]). Acid production from sugars using peptone as the nitrogen source: permanent or transient acidification, results read daily for 5 days at $30^{\circ} \mathrm{C}$. The test was recorded as positive if acid was produced at any time during this period (two states [10, p. 293]): $\S$ fructose, $\S$ galactose, $\S$ glucose, \& glycerol, § lactose, § maltose, § mannitol, § mannose, § saccharose, § salicin, § sorbitol, $\S$ starch, § xylose.

Sensitivity to antibiotics. Average width of inhibition rings on MA plate surrounding two 6-mm disks containing stated amount of antibiotic: $\S$ penicillin, $10 \mathrm{U}$ (seven states, class boundaries $20,16,12$, 8,4 , and $0 \mathrm{~mm}$ ), § streptomycin, $10 \mu \mathrm{g}$ (three states, class boundaries 8 and $4 \mathrm{~mm}$ ), $\S$ kanamycin, $30 \mu \mathrm{g}$ (three states, see streptomycin), § terramycin, 30 $\mu \mathrm{g}$ (three states, see streptomycin), $\S$ novobiocin, 30 $\mu \mathrm{g}$ (four states, class boundaries 16,12 , and $8 \mathrm{~mm}$ ).

\section{Mathematical Procedures}

Multistate encoding of results. The most positive answer to each test was encoded as 6 and the most negative as 0 . According to the nature of the test, the results were encoded as 6 or 0 (two states), as 6 , 3 , or 0 (three states), as $6,4,2$, or 0 (four states), or as $6,5,4,3,2,1$, or 0 (seven states). The results of two highly correlated tests (such as the two motility tests) were sometimes cumulated to form a single three-state character $(2,1$, and 0 positive results encoded as 6,3 , and 0 , respectively). A "no-comparison" symbol was used (i) when the test could not be validly performed (usually for lack of growth in the test medium) and (ii) when the result could have been predicted from that of a prior test (e.g., when no acid was produced from glucose, the results were also automatically negative for the other sugars, a motile strain was necessarily flagellated, etc).

The encoded results of the 63 selected test strains (Tables 1 and 2) were lodged in the World Data Center for Microorganisms, Brisbane, Australia. 
Weighting of sugar fermentation results. Since the total contribution of the sugar fermentation tests was disproportionately large, the acid production from 12 sugars other than glucose was given only one-third the normal weight in the calculation of the similarity coefficients. This weighting was introduced mainly to reduce the artificial increase in the similarity coefficient of strains which have in common only the fact that they ferment few sugars (numerous $0-0$ comparisons).

Distances and similarity coefficients. To compute the distance of two strains, the difference of the encoded figures was computed for each multistate character (except when a no-comparison symbol turned up), and the absolute values of these differences were summated over all characters. The distance $D$ was defined as the quotient of this sum by the maximum possible sum of differences. For example, if A scores $0,6,3,3$ on four tests and $B$ scores 6,3 , no comparison, 0 , then $D$ is $(6+3+3) /(3 \times 6)=$ 0.6667 .

The similarity coefficient was defined by $\mathrm{SC}=(1$ $-D) \times 100$ (in the above example, $\mathrm{SC}=33.33$ ). The values of $\mathrm{SC}$ formed a normal distribution with a mean of 67.35 and a standard deviation of 8.42. The two tails of the distribution (values outside of the interval defined by the mean \pm 1.96 standard deviation) each contained almost exactly the expected $2.5 \%$ of all values.

Reproducibility of analyses. The complete analysis of five isolates was repeated independently. The new results were encoded and compared to those of the first analysis of the same strain. The resulting SC ranged from 90.2 to 94.6 and averaged 92.2 . It follows that two strains having an $\mathrm{SC}$ in excess of 90 are virtually identical.

Clustering procedure. Junctions at decreasing similarity levels were established by an unweighted pair-group method using arithmetic averages (19). The dendrogram thus obtained was then ordered. Each element being joined to a cluster was placed on that side of the cluster where its SC to the outermost element in the cluster was the higher. Similarly, of the four relative positions which are possible when two clusters are joined, that position was chosen in which the most similar external elements of both clusters were next to each other. Larger clusters were ordered by a trial-and-error process using average similarity tables (e.g., Table 3 ) and two computer-generated similarity matrices as a guide. The first matrix classically emphasized the higher SC values, the aim being to bring these as close as possible to the diagonal; the second matrix emphasized the lower SC values and served mainly to warn against placing very dissimilar elements close together.

Additive binary coding. Each of the 63 original $n$ state characters was broken down into $n-1$ binary alternatives; 109 binary tests were obtained. For example, the four-state character "diameter of colonies" with the alternatives $>12 \mathrm{~mm}$ (encoded as 6), 6 to $11 \mathrm{~mm}$ (encoded as 4), 3 to $5 \mathrm{~mm}$ (encoded as 2) and $<2 \mathrm{~mm}$ (encoded as 0 ) was replaced by the three binary tests $>12 \mathrm{~mm},>6 \mathrm{~mm},>3 \mathrm{~mm}$, yielding the four combinations $000,001,011$, and 111 . The list of binary characters and the encoded results were also lodged in the World Data Center for Microorganisms, Brisbane, Australia.

\section{RESULTS \\ Selection of Tests}

Tests yielding invariant results. All our isolates from marine sediments shared the following properties: gram positive in young broth culture; mesophilic (optimum 30 or $37^{\circ} \mathrm{C}$ ); positive to a sensitive test for catalase (flooding of plates with $1 \% \mathrm{H}_{2} \mathrm{O}_{2} ;$ a Clostridium perfringens strain was used as a negative control) (the catalase test described among the selected tests [see Materials and Methods] in which $10 \% \mathrm{H}_{2} \mathrm{O}_{2}$ was used was often negative); no indole produced; no gas produced from sugars; no alkalinization of Koser medium supplemented with glycerol, sodium ascorbate, benzoate, formate, oxalate, propionate, or tartrate; insensitive to polymyxin in disk test.

The following tests yielded uniform results with one to three exceptions out of 138: one spore per sporangium (exception: strain VUB 12 , see below); spores oval (exception: strain VUB 85 had round spores resembling those of test strain Bacillus sphaericus CIP 5125); no hydrogen sulfide produced; no acid produced from arabinose, dulcitol, inositol, raffinose, or rhamnose with peptone as the nitrogen source.

The above results describe constant features of our isolates from marine sediments, but the uniformity of these isolates' results renders the tests useless for purposes of numerical taxonomy.

Other rejected tests. The following tests were rejected because they failed to give clearcut or reproducible results in our hands: presence of capsules, anaerobic growth on BBL anaerobic agar without dextrose or Eh indicator, production of ammonia from peptone, hydrolysis of phenolphthalein monophosphate, peptonization of litmus milk, sensitivity to sulfafurazole.

Other tests were dropped because their results were highly correlated with those of a similar test. For example, 11 of 16 antibiotic sensitivity tests and the "presence of vacuoles" (identical results to presence of lipid droplets) were disregarded for that reason. The final selection left 63 multistate characters (see Materials and Methods) with a total of 172 states, which were used for computation of similarities.

\section{Cluster Formation}

Main clusters. The clustering procedure used to gradually join our 138 strains resulted 
in the formation of two clusters, A and B, of 63 and 74 elements, respectively, and in their eventual union at similarity level 62.7 . The only remaining element, strain VUB 71 , was finally joined at level 58.9. Figures $1 \mathrm{~A}$ and $1 \mathrm{~B}$ show the dendrogram of the two clusters and Table 3 gives their intragroup and intergroup average similarity. The large difference between the intergroup average similarity of 62.8 and the intragroup averages (about 72) validates the separation of the two main clusters.

Structure of cluster $A$. This cluster contained two subclusters, $A 1$ and $A 2$, of 27 and 21 strains, respectively. Again, the validity of their separation was established by their high intragroup similarity averages and much lower intergroup average (Table 4). Groups $\mathrm{A} 1$ and A2 were of sufficient size and coherence to be considered as phenons. A description of their centrotype strains (defined here as the strain with the highest average similarity to the other elements of the group) is given in Table 5.

The remaining 15 strains of cluster $\mathrm{A}$ formed two loose subclusters (A3).

Structure of cluster $B$. The dendrogram of cluster B did not immediately suggest an obvious subdivision. The clustering process showed continuous growth around a main nucleus of 11 similar strains in group B1 and around several smaller nuclei. The clusters B2, B3, and B4, which were formed at similarity level 75, joined $B 1$ in rapid succession below that level (Fig. 1B). The four clusters B1 to B4 each had 10 to 23 strains and a high internal similarity average (Table 4); they were therefore considered as phenons. The centrotype strains are described in Table 5.

Again, a residue of 18 strains of low coherence was left (B5).

\section{Diagnostic Value of Tests}

Selection of most discriminating tests. For each of the 109 binary tests, the proportion of strains yielding positive results was computed, as was the absolute value $d$ of the difference in these proportions between the two groups of strains mentioned in each section of Table 6 . If the largest value in the set of $d$ values regarding the same feature (original multistate character) exceeded 0.55 , it was entered into Table 6 . All differences in proportion of positives in excess of 0.55 were significant at the $1 \%$ level. Sections $a$ and $b$ of Table 6 list the tests which discriminated primarily either between clusters $\mathrm{A}$ and $\mathrm{B}$ (disregarding the less characteristic, marginal strains) or between phenons A1 and A2. The most discriminating features within cluster B were searched for in the re- verse order of the clustering process. The last joined phenon, B4, was first singled out and compared to the pool of $\mathrm{B} 1+\mathrm{B} 2+\mathrm{B} 3$ (section c), and then B3 was compared to B1 + B2 (section d), and finally B1 was compared to B2 (section e).

Comparison of clusters A and B. The feature with the highest discriminating power was the Voges-Proskauer (VP) test. All strains of phenons $A 1$ and $A 2$ were $\mathrm{VP}+$ and all strains of phenons B1 to B4 were VP-. Only the marginal groups A3 and B5 gave mixed results. The reproducibility of this test was excellent when long incubation times (5 days at $30^{\circ} \mathrm{C}$ ) were used. When results were read after only 2 days, five of the $54 \mathrm{VP}+$ strains yielded negative or slightly positive results, even though full development of the culture was attained. These strains were therefore slow acetoin producers. The VP reaction of all reference strains (Table 2 , serial no. 1-12) was as expected from the species description.

All strains of phenons A1 and A2 had small cells (dimensions less than 0.9 by $4.5 \mu \mathrm{m}$ ), small $(<3.0 \mu \mathrm{m})$ nonbulging sporangia, and thin-walled spores. All were motile, tolerated $7 \% \mathrm{NaCl}$ and $\mathrm{pH}$ 5.7, dizested gelatin, and formed acid from glucose with peptone as the source of nitrogen. All but a few strains grew at $44^{\circ} \mathrm{C}$, digested pectate, and produced abundant catalase.

In cluster B, size, motility, tolerance of $7 \%$ $\mathrm{NaCl}$, growth at $\mathrm{pH} 5.7$ and at $44^{\circ} \mathrm{C}$, abundance of catalase production, digestion of gelatin, and acid production from glucose were variable. Thirteen strains had thick-walled spores and three of these (VUB 71, 83 and 85) had clavate sporangia; the other strains had nonbulging sporangia. All our isolates except one (VUB 85) had oval spores.

Features distinguishing phenons. A relatively long list of features, headed by the amylase test, clearly distinguished phenons $\mathrm{A} 1$ and A2. The phenons of cluster B were less clearly differentiated. Phenon B2 was distinguished by the ability of all its strains to reduce nitrate and to grow anaerobically. The strains of phenon B3 were distinguished by their ability to grow at $\mathrm{pH} 5.7$ and those of $\mathrm{B} 4$ were distinguished by their inability to ferment saccharose. The strains of phenon B1 had the fewest distinctive features. This was in agreement with the nuclear role of this phenon in the clustering process (see above) and with the high intergroup similarity averages between $\mathrm{B} 1$ and the other groups of cluster B (Table 4).

Motility, chitinolysis, and exceptional features. Motility: the nonmotile strains were dis- 


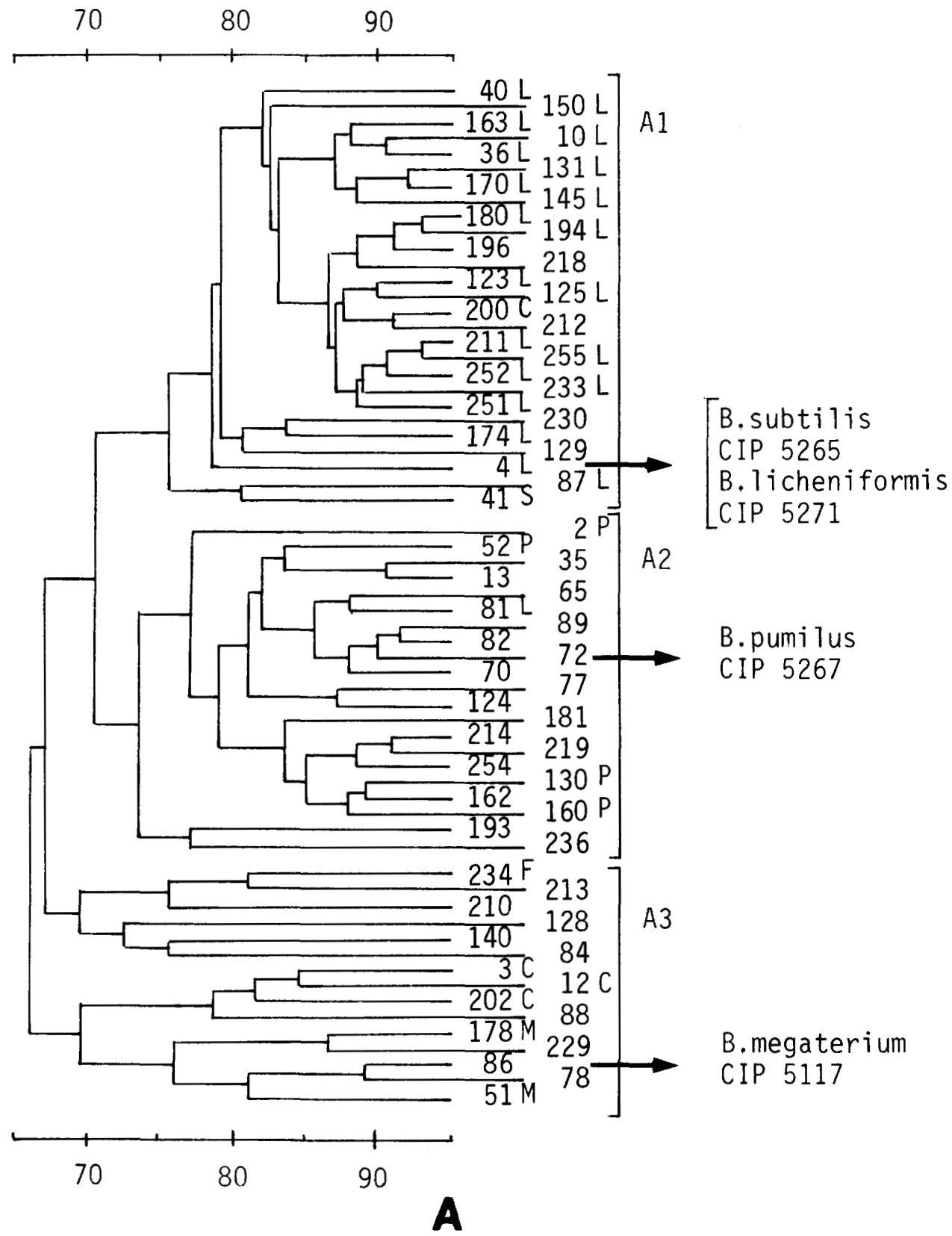

Fig. 1. Dendrogram, groups, and species identification. Left to right: similarity scale and junctions; no. of $V U B$ strain and species identification, if any (C, cereus; $F$, firmus; $L$, licheniformis; $M$, megaterium; $P$, pumilus; $S$, subtilis); brackets giving limits of groups; reference strains shown next to mosi similar VUB strain (arrow). Only those reference strains are shown which developed at least one similarity coefficient in the upper $2.5 \%$ category when compared to the VUB strains. (A) Cluster A; (B) cluster B.

tributed unevenly and the highest proportion was found in groups B2 and B3. Overall, this feature was not nearly as useful in our hands as the Voges-Proskauer test in classification. The two motility tests, stab inoculation and phasecontrast observation, sometimes gave discrepant results. To further complicate the picture, 33 of our strains were flagellated even though 


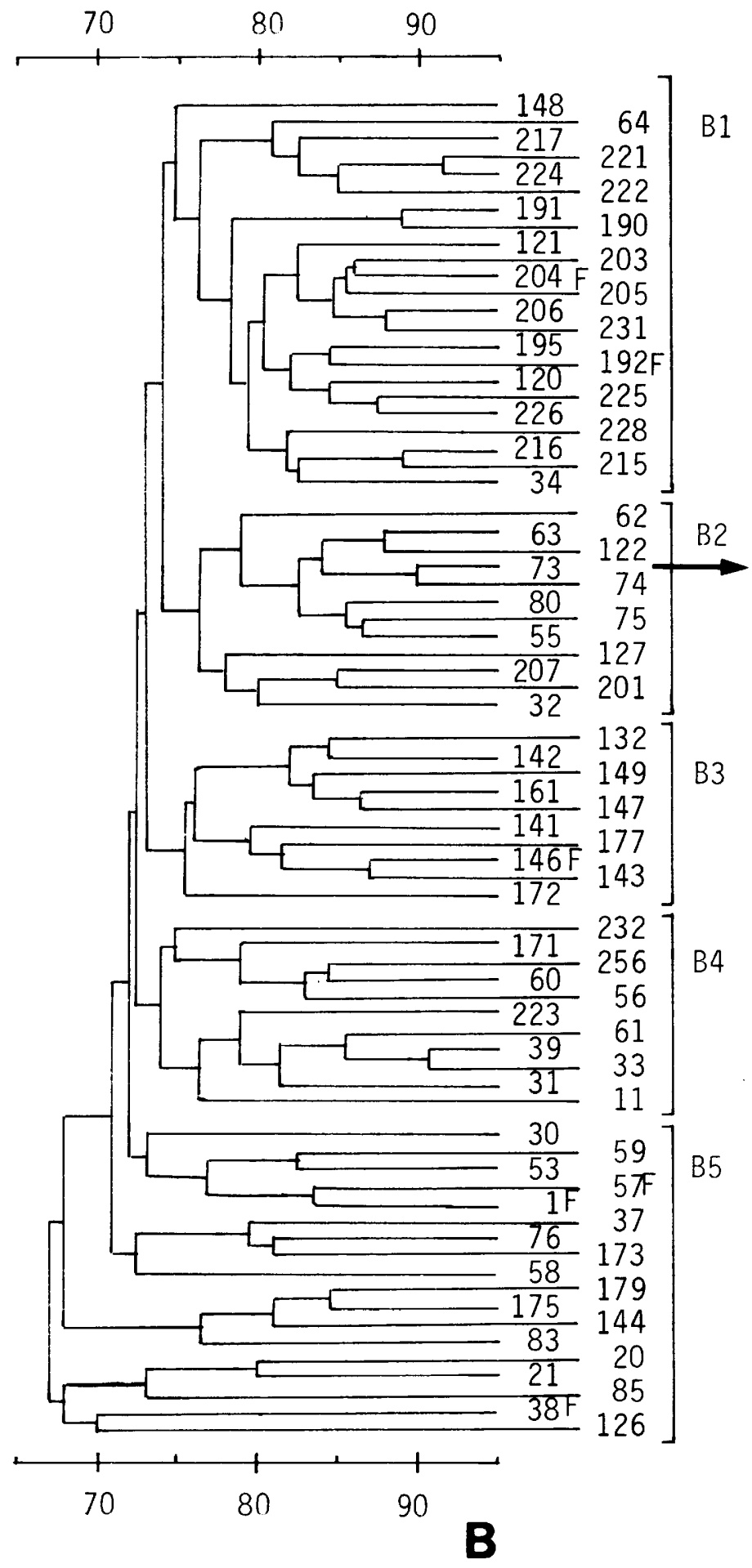

B. firmus

CIP 5269 
nonmotile by both tests. It is of course possible that these strains scored as nonmotile because physiological conditions for their motility were not met and that the same strains would score as motile under different conditions. These facts do not favor the use of motility as a primary criterium within the genus Bacillus, and certainly not the segregation of the nonmotile strains into a separate genus Bacteridium (17).

Chitinolysis: 21 of the 27 strains of phenon A1 and six other strains were chitinolytic. These results are in full agreement with those of de Barjac and Cosmao-Dumanoir (3) who found that 14 out of 15 strains assigned to Bacillus licheniformis were chitinolytic. On the other hand, they disagree with the findings of Denis (Ph.D. thesis, University of Poitiers, Poitiers, France, 1971) who obtained only negative results for Bacillus strains of marine origin assigned to 11 species, including $B$. licheniformis.

Two-spored strain: isolate VUB 12 (identified as Bacillus cereus) formed two spores per sporangium. Except for this peculiarity, this strain had little in common with previously described two-spored rods, the species Bacillus viridiglaucescens Sack (17) and the several species isolated from tadpole intestine (11).

Thermotolerance: the exceptional thermotolerance of some of our Bacillus isolates (up to $75^{\circ} \mathrm{C}$, i.e., as high as the most tolerant $B$. stearothermophilus strains [13]) has been described previously (4). The most tolerant strains were distributed at random along the dendrogram.

\section{Attempts at Conventional Identification}

Cluster A. Twenty of the 27 strains of phenon $A 1$ were identified as $B$. licheniformis, one was identified as Bacillus subtilis, and one was identified as $B$. cereus. The reference strains Bacillus subtilis CIP 5265 and B. licheniformis CIP 5271 developed their highest individual and average similarity values with the strains of this phenon (Fig. 1A and Table 7). Of the 21 strains of phenon A2, only four were identified as Bacillus pumilus and one was identified as $B$. licheniformis. The type strain $B$. pumilus CIP 5267 mapped centrally in this phenon (Fig. $1 \mathrm{~A}$ ), and its average similarity to phenon A2 was markedly higher than to any other phenon (Table 7). The 16 unidentifiable strains all belonged to the "subtilis spectrum," but could not be unambiguously assigned to $B$. subtilis, $B$. pumilus, or $B$. licheniformis. The often noted similarity of these three species was also emphasized by the high degree of similarity among their type strains (average SC of strains CIP 5265, CIP 5271, and CIP 5267: 75.9). Three of the 15 marginal strains forming group A3 were identified as $B$. cereus, two were identified as Bacillus megaterium, and one was identified as Bacillus firmus. The reference strain $B$. megaterium CIP 5117 also mapped in A3 (Fig. 1A and Table 7), but the $B$. cereus reference strain could not be easily mapped (Table 7).

Cluster B. Six of the 74 strains in cluster B were identified by the two keys of Gordon (12) as $B$. firmus. The reference strain $B$. firmus CIP 5269 mapped in phenon B2 (Fig. 1B) and had relatively high average similarities with phenons B1, B2, and B4 (Table 7). The remaining 68 strains could not be identified unambiguously. Twenty of these strains were identified as $B$. firmus by one key and as $B$. megaterium (13 cases) or Bacillus coagulans (seven cases) by the other key. The firmus-megaterium alternative was at first surprising since the two species differ by at least three clear-cut characters, i.e., width of cells, presence of lipid drop-

TABLE 3. Intra- and intergroup average similarities for main clusters ${ }^{a}$

\begin{tabular}{ccc}
\hline Cluster & Cluster A & Cluster B \\
\hline A (63 strains) & $\frac{71.9}{62.8}$ & \\
B (74 strains) & 72.3 \\
\hline
\end{tabular}

${ }^{a}$ Intragroup averages are underlined.

TABLE 4. Intra-and intergroup average similarities for groups as shown in Fig. $1^{a}$

\begin{tabular}{|c|c|c|c|c|c|c|c|c|}
\hline \multirow{2}{*}{ Group } & \multicolumn{3}{|c|}{ Cluster A } & \multicolumn{5}{|c|}{ Cluster B } \\
\hline & A1 & A2 & A3 & B1 & B2 & B3 & B4 & B5 \\
\hline A1 (27 strains) & 82.0 & & & & & & & \\
\hline A2 (21 strains) & 70.5 & 79.6 & & & & & & \\
\hline A3 (15 strains) & 66.5 & $\overline{66.3}$ & $\underline{68.1}$ & & & & & \\
\hline B1 (23 strains) & 62.2 & 68.2 & $\overline{68.6}$ & 78.8 & & & & \\
\hline B2 (12 strains) & 59.9 & 64.4 & 66.9 & 74.2 & 79.4 & & & \\
\hline B3 (10 strains) & 61.1 & 67.4 & 65.4 & 73.6 & $\overline{72.3}$ & 78.2 & & \\
\hline B4 (11 strains) & 56.1 & 63.7 & 64.4 & 73.6 & 71.8 & 69.8 & 76.4 & \\
\hline B5 (18 strains) & 55.1 & 62.4 & 63.3 & 69.6 & 69.6 & 69.5 & 69.0 & 68.8 \\
\hline
\end{tabular}

${ }^{a}$ Intragroup averages are underlined. 
lets in the cytoplasm, and growth at $\mathrm{pH}$ 5.7. The eight possible combinations of results to these three tests (including the formulas +++ of $B$. megaterium and --- of $B$. firmus) were all encountered among the $84 \mathrm{VP}$ - strains (Table 8), and their frequencies were close to expectation assuming no correlation between the three characters. Although cell width covered a wide range (from 0.4 to $1.7 \mu \mathrm{m}$ ), its distribution was unimodal (mean and standard deviation, $0.89 \pm 0.29 \mu \mathrm{m})$. In addition, 22 strains had a width of 0.9 to $1.2 \mu \mathrm{m}$, i.e., out of the normal range of both $B$. firmus and $B$. megaterium. Lipid droplets, when present, were more or less abundant, and the inhibition of growth at $\mathrm{pH}$
5.7 was sometimes incomplete. Thus, the three features distinguishing $B$. firmus and $B$. megaterium appeared in an uncorrelated way and were also expressed to various degrees.

Some strains were identified by one of Gordon's keys as $B$. coagulans, but this identification was untenable as these strains differed from the species description by being able to grow in the presence of $7 \% \mathrm{NaCl}$ and unable to grow in anaerobiosis.

In conclusion, the performance of the conventional nomenspecies in identifying our isolates from marine sediments was poor, except for the strains of phenon A1, most of which were identified as $B$. licheniformis. Of the remaining 111

TABLE 5. Description of centrotype strains ${ }^{a}$

\begin{tabular}{|c|c|c|c|c|c|c|}
\hline \multirow{2}{*}{ Characteristic } & $\mathrm{A} 1^{b}$ & A2 & B1 & B2 & B3 & B4 \\
\hline & $\begin{array}{l}\text { VUB } \\
211^{c}\end{array}$ & $\begin{array}{c}\text { VUB } \\
72\end{array}$ & $\begin{array}{l}\text { VUB } \\
231\end{array}$ & $\begin{array}{c}\text { VUB } \\
73\end{array}$ & $\begin{array}{l}\text { VUB } \\
149\end{array}$ & $\begin{array}{c}\text { VUB } \\
33\end{array}$ \\
\hline \multicolumn{7}{|l|}{ Morphology of vegetative cells } \\
\hline Avg. length $(\mu \mathrm{m})$ & 4.1 & 2.4 & 3.5 & 5.1 & 3.5 & 3.8 \\
\hline Avg. width $(\mu \mathrm{m})$ & 0.8 & 0.6 & 0.8 & 0.9 & 1.6 & 0.6 \\
\hline Chains of 4 or more cells in NB & + & - & + & + & + & - \\
\hline Ghosts in old NB culture & + & + & + & + & + & + \\
\hline Constancy of gram + reaction & + & + & + & + & + & + \\
\hline Lipid droplets in cytoplasm & - & - & + & + & - & + \\
\hline Motility (stab, microscopy) &,++ &,++ &,++ &,-+ &,-- &,++ \\
\hline Flagella & + & + & + & + & + & + \\
\hline \multicolumn{7}{|l|}{ Spores and sporangia } \\
\hline Spore morphology: shape & Oval & Oval & Oval & Oval & Oval & Oval \\
\hline Position, wall thickness & ST, thin & $\mathrm{V}$, thin & $\mathrm{V}$, thin & $\mathrm{C}$, thin & $\mathrm{C}$, thin & $\mathrm{V}$, thin \\
\hline Sporangium: avg. length $(\mu \mathrm{m})$ & 2.8 & 2.0 & 2.1 & 1.9 & 2.3 & 2.3 \\
\hline Bulging, chain formation &,-- &,-- &,-- &,-- &,-+ &,-- \\
\hline \% Spores after 10 days in NB & 12 & 25 & 5 & 27 & 20 & 47 \\
\hline All spores killed at $80^{\circ} \mathrm{C}$ & - & - & - & - & - & - \\
\hline All spores killed at $100^{\circ} \mathrm{C}$ & - & - & + & + & + & + \\
\hline \multicolumn{7}{|l|}{ Macroscopic morphology } \\
\hline \multicolumn{7}{|l|}{ Colonies on MA: } \\
\hline Shape & Irreg. & Circular & Circular & Circular & Circular & Circular \\
\hline Margin & Filam. & Entire & Entire & Entire & Entire & Entire \\
\hline Elevation & Raised & Raised & Convex & Flat & Flat & Flat \\
\hline Brilliance & Dull & Glist. & Glist. & Glist. & Glist. & Glist. \\
\hline Opacity & Opaque & Opaque & Opaque & Opaque & Opaque & Opaque \\
\hline Color & Pink & White & Yellow & Orange & Orange & Orange \\
\hline Color intensity & Faint & Faint & Faint & Medium & Medium & Faint \\
\hline $\begin{array}{l}\text { Diam. (mm) of standard col- } \\
\text { ony }\end{array}$ & 20 & 7 & 13 & 10 & 8 & 7 \\
\hline \multicolumn{7}{|l|}{ Growth in NB: } \\
\hline Turbidity & \pm & \pm & \pm & + & - & - \\
\hline Sediment & Fine & Granular & Granular & Fine & Fine & $\begin{array}{l}\text { Granu- } \\
\text { lar }\end{array}$ \\
\hline Pellicle & + & + & - & - & - & - \\
\hline \multicolumn{7}{|l|}{ Tolerances for growth in NB } \\
\hline $\begin{array}{l}\text { Growth promoted by } 3.5 \% \\
\mathrm{NaCl}\end{array}$ & - & - & - & - & - & - \\
\hline $\mathrm{NaCl}$ tolerated $(\%)$ & 10 & 10 & 10 & 15 & 30 & 20 \\
\hline $\begin{array}{l}\text { Growth in } 5 \text { days in } \mathrm{NB} \text { at } \mathrm{pH} \\
5.7,30^{\circ} \mathrm{C}\end{array}$ & + & + & - & - & + & - \\
\hline Growth at $\mathrm{pH} 6.0,60^{\circ} \mathrm{C}$ & - & + & - & + & - & - \\
\hline
\end{tabular}


Int. J. Syst. Bacteriol.

TABLE 5-Continued

\begin{tabular}{|c|c|c|c|c|c|c|}
\hline \multirow[b]{2}{*}{ Characteristic } & $A 1^{b}$ & A2 & B1 & B2 & B3 & B4 \\
\hline & $\begin{array}{l}\text { VUB } \\
211^{c}\end{array}$ & $\begin{array}{c}\text { VUB } \\
72 \\
\end{array}$ & $\begin{array}{l}\text { VUB } \\
231 \\
\end{array}$ & $\begin{array}{c}\text { VỤB } \\
73\end{array}$ & $\begin{array}{l}\text { VUB } \\
149 \\
\end{array}$ & $\begin{array}{c}\text { VUB } \\
33\end{array}$ \\
\hline $\begin{array}{l}\text { Maximum growth temp (C) in } \\
\text { NB ( } 7 \text { days) }\end{array}$ & $57^{\circ}$ & $57^{\circ}$ & $37^{\circ}$ & $57^{\circ}$ & $44^{\circ}$ & $70^{\circ}$ \\
\hline \multicolumn{7}{|l|}{$\begin{array}{l}\text { Substrate utilization and modi- } \\
\text { fication }\end{array}$} \\
\hline $\begin{array}{l}\text { Anaerobic growth in glucose } \\
\text { broth }\end{array}$ & + & - & - & - & - & - \\
\hline Simmons citrate: growth & + & + & + & - & - & + \\
\hline Alkalinization & - & - & - & - & - & - \\
\hline $\begin{array}{l}\text { Koser medium + fumarate: } \\
\text { growth }\end{array}$ & + & + & + & - & - & - \\
\hline Alkalinization & + & + & - & - & - & - \\
\hline $\begin{array}{l}\text { Litmus milk: coagulation in } 28 \\
\text { days }\end{array}$ & + & + & + & + & + & + \\
\hline Peptonization, reduction &,++ &,++ &,+ \pm &,++ &,+- &,-+ \\
\hline $\begin{array}{l}\text { Acidification, alkalinization } \\
\text { Enzymatic activities and prod- } \\
\text { ucts (other than acid) }\end{array}$ &,-- &,-- &,-- &,+- &,-- &,-- \\
\hline Digestion of casein & + & + & + & + & + & + \\
\hline Liquefaction of gelatin & + & + & + & + & + & + \\
\hline Digestion of starch, pectate &,++ &,-+ &,-+ &,-- &,-- &, \pm- \\
\hline Digestion of chitin & + & - & - & - & - & - \\
\hline $\begin{array}{l}\text { Production of abundant cata- } \\
\text { lase }\end{array}$ & + & + & + & + & - & - \\
\hline Production of oxidase & \pm & - & \pm & + & + & + \\
\hline Reduction of nitrate, of nitrite &,++ &,++ &,-- &,++ &,-- &,-- \\
\hline Hydrolysis of egg-yolk lecithin & + & + & + & + & + & + \\
\hline Hydrolysis of Tween 80 & - & + & - & + & - & - \\
\hline Decomposition of urea & + & - & - & - & - & - \\
\hline Hydrolysis of esculin & + & + & + & - & + & - \\
\hline Production of indole & - & - & - & - & - & - \\
\hline Production of acetoin & + & + & - & - & - & - \\
\hline Production of hydrogen sulfide & - & - & - & - & - & - \\
\hline \multicolumn{7}{|l|}{ Fermentation of glucids } \\
\hline Methyl red test & - & + & - & - & - & - \\
\hline Gas from glucids & - & - & - & - & - & - \\
\hline Anaerobic Hugh-Leifson test: & & & & & & \\
\hline $\begin{array}{l}\text { growth } \\
\text { Acidification }\end{array}$ & $\begin{array}{l}+ \\
+\end{array}$ & $\begin{array}{l}+ \\
+\end{array}$ & - & $\begin{array}{l}+ \\
-\end{array}$ & $\begin{array}{l}- \\
-\end{array}$ & $\begin{array}{l}- \\
-\end{array}$ \\
\hline Acid from glucose $\left(\mathrm{NH}_{4}^{+}\right)$ & + & + & + & - & - & - \\
\hline \multicolumn{7}{|l|}{$\begin{array}{l}\text { Acid production from (pep- } \\
\text { tone): }\end{array}$} \\
\hline Arabinose, dulcitol, fructose &,,--+ &,,--+ &,,--+ &,,--+ &,,--+ &,,--+ \\
\hline Galactose, glucose, glycerol &,,-+- &,,+++ &,,-++ &,,-+- &,,++- &,,-+- \\
\hline Inositol, lactose, maltose &,,--+ &,,--- &,,--+ &,,--+ &,,--- &,,--+ \\
\hline $\begin{array}{l}\text { Mannitol, mannose, raffi- } \\
\text { nose }\end{array}$ &,,++- &,,++- &,,++- &,,++- &,,++- &,,++- \\
\hline $\begin{array}{l}\text { Rhamnose, saccharose, sali- } \\
\text { cin }\end{array}$ &,,-++ &,,-++ &,,-++ &,,-+- &,,-++ &,,--- \\
\hline $\begin{array}{c}\text { Sorbitol, starch, xylose } \\
\text { Sensitivity to antibiotics (mm) }\end{array}$ &,,-+- &,,--- &,,--- &,,-+- &,,+-+ &,,--+ \\
\hline $10 \mathrm{U}$ penicillin & 5 & 13 & 10 & 13 & 17 & 19 \\
\hline $10 \mu \mathrm{g}$ streptomycin & 2 & 5 & 4 & 5 & 6 & 7 \\
\hline $30 \mu \mathrm{g}$ kanamycin & 6 & 6 & 5 & 8 & 8 & 8 \\
\hline $30 \mu \mathrm{g}$ terramycin & 2 & 3 & 5 & 5 & 7 & 6 \\
\hline $30 \mu \mathrm{g}$ novobiocin & 10 & 11 & 10 & 12 & 11 & 12 \\
\hline
\end{tabular}

${ }^{a}$ Abbreviations: +, positive; \pm , slightly positive; -, negative; C, central; filam., filamentous; glist., glistening; irreg., irregular; ST, subterminal; V, variable.

${ }^{b}$ Phenon.

" Centrotype strain number. 
strains, only 17 , or less than one in six, was identifiable. Based on the few positive identifications and the mapping of reference strains, phenon A2 and cluster $B$ were loosely related to the conventional species $B$, pumilus and $B$. firmus, respectively.

\section{Comparison with Numerical Taxonomic System of Bonde}

Bonde $(5,6)$ was able to assign a wide spectrum of mesophilic Bacillus strains to 10 phenons.

TABLE 6. Most discriminating binary tests

\begin{tabular}{|c|c|c|c|c|c|c|c|c|c|}
\hline \multirow{2}{*}{ Tests } & \multicolumn{8}{|c|}{ No. of positive strains } & \multirow{2}{*}{$\begin{array}{c}\text { Difference }(d) \\
\text { in proportion } \\
\text { of positive } \\
\text { strains } \\
\end{array}$} \\
\hline & $\begin{array}{c}\text { A1 } \\
(27)^{a} \\
\end{array}$ & $\begin{array}{l}\text { A2 } \\
(21)\end{array}$ & $\begin{array}{c}\text { A3 } \\
(15)\end{array}$ & $\begin{array}{c}\text { B1 } \\
(23)\end{array}$ & $\begin{array}{c}\text { B2 } \\
(12)\end{array}$ & $\begin{array}{l}\text { B3 } \\
(10)\end{array}$ & $\begin{array}{c}\text { B4 } \\
(11)\end{array}$ & $\begin{array}{c}\text { B5 } \\
(17)\end{array}$ & \\
\hline \multicolumn{10}{|l|}{$\begin{array}{l}\text { a. Distinguishing clusters } A \text { and } B \text { (ex- } \\
\text { cept marginal strains) })^{b}\end{array}$} \\
\hline Acetoin produced (VP+) & 27 & 21 & 5 & 0 & 0 & 0 & 0 & 1 & 1.00 \\
\hline Pellicle formed on NB & 26 & 13 & 5 & 0 & 0 & 0 & 0 & 0 & 0.81 \\
\hline Pectate digested & 25 & 20 & 5 & 6 & 0 & 0 & 1 & 0 & 0.81 \\
\hline Acid produced from salicin (peptone) & 26 & 19 & 10 & 12 & 0 & 2 & 0 & 2 & 0.69 \\
\hline Motile (stab inoculation) & 27 & 17 & 9 & 7 & 1 & 2 & 7 & 4 & 0.61 \\
\hline $\begin{array}{l}\text { Spores retain viability after } 20 \text { min at } \\
100^{\circ} \mathrm{C}\end{array}$ & 20 & 10 & 5 & 2 & 0 & 1 & 1 & 0 & 0.55 \\
\hline \multirow{2}{*}{\multicolumn{10}{|c|}{$\begin{array}{l}\text { Growth at pH } 5.7 \text { ( } d=0.75 \text {, see section } \\
\text { d); Hugh-Leifson test }(d=0.57 \text {, see } \\
\text { section b) }\end{array}$}} \\
\hline \multicolumn{8}{|l|}{ b. Distinguishing phenons $\mathrm{A} 1$ and $\mathrm{A} 2^{c}$} & & \\
\hline Starch digested & 27 & 2 & 12 & 11 & 5 & 7 & 4 & 6 & 0.91 \\
\hline Penicillin disk: inhibition ring $>8 \mathrm{~mm}$ & 4 & 21 & 2 & 21 & 11 & 9 & 8 & 14 & 0.85 \\
\hline Nitrite reduced & 24 & 1 & 7 & 0 & 2 & 0 & 1 & 1 & 0.84 \\
\hline Chitin digested & 21 & 0 & 5 & 0 & 0 & 0 & 0 & 1 & 0.78 \\
\hline Acid produced from maltose (peptone) & 22 & 1 & 13 & 15 & 9 & 0 & 4 & 2 & 0.77 \\
\hline Colonies matte & 20 & 0 & 0 & 0 & 3 & 4 & 0 & 0 & 0.74 \\
\hline $\begin{array}{l}\text { Acid anaerobically produced (Hugh- } \\
\text { Leifson) }\end{array}$ & 24 & 4 & 5 & 1 & 0 & 0 & 0 & 0 & 0.70 \\
\hline Diameter of standard colonies $\geq 12 \mathrm{~mm}$ & 22 & 3 & 5 & 8 & 6 & 3 & 0 & 3 & 0.67 \\
\hline Chains of 4 or more cells formed & 22 & 3 & 12 & 22 & 12 & 9 & 4 & 13 & 0.67 \\
\hline $\begin{array}{l}\text { Streptomycin disk: inhibition ring }>4 \\
\mathrm{~mm}\end{array}$ & 5 & 17 & 9 & 16 & 11 & 9 & 11 & 14 & 0.62 \\
\hline Methyl red test positive & 4 & 16 & 7 & 4 & 0 & 0 & 1 & 0 & 0.61 \\
\hline \multicolumn{10}{|l|}{$\begin{array}{l}\text { c. Distinguishing phenon B4 from B1 + } \\
\text { B2 + B3 (pooled) })^{d}\end{array}$} \\
\hline $\begin{array}{l}\text { Acid produced from saccharose (pep- } \\
\text { tone) }\end{array}$ & 27 & 18 & 13 & 17 & 10 & 8 & 0 & 10 & 0.78 \\
\hline Pigmentation medium to intense & 8 & 8 & 1 & 12 & 10 & 8 & 1 & 4 & 0.58 \\
\hline Acid produced from glucose (peptone) & 27 & 21 & 15 & 22 & 12 & 8 & 4 & 10 & 0.57 \\
\hline Chains formed ( $d=0.59$, see section b) & & & & & & & & & \\
\hline \multicolumn{10}{|l|}{$\begin{array}{l}\text { d. Distinguishing phenon B3 from B1 + } \\
\text { B2 (pooled) }\end{array}$} \\
\hline Growth in NB at $\mathrm{pH} 5.7,30^{\circ} \mathrm{C}$ & 27 & 21 & 12 & 1 & 4 & 9 & 0 & 8 & 0.76 \\
\hline Lipid droplets present & 4 & 2 & 11 & 13 & 11 & 0 & 10 & 5 & 0.69 \\
\hline Growth in $\mathrm{NB}$ at $44^{\circ} \mathrm{C}$ & 26 & 19 & 12 & 3 & 8 & 9 & 6 & 12 & 0.59 \\
\hline $15 \% \mathrm{NaCl}$ tolerated & 10 & 7 & $\cdot 4$ & 1 & 7 & 8 & 1 & 5 & 0.57 \\
\hline \multicolumn{10}{|l|}{$\begin{array}{l}\text { Acid from maltose }(d=0.69 \text {, see section } \\
\text { b) }\end{array}$} \\
\hline \multicolumn{10}{|l|}{ e. Distinguishing phenons $\mathrm{B} 1$ and $\mathrm{B} 2^{f}$} \\
\hline Nitrate reduced & 27 & 12 & 11 & 5 & 12 & 1 & 5 & 12 & 0.78 \\
\hline Anaerobic growth (Hugh-Leifson) & 26 & 14 & 11 & 6 & 12 & 2 & 3 & 1 & 0.74 \\
\hline
\end{tabular}

${ }^{a}$ Number in parentheses indicates number of strains.

${ }^{b} d=\left|p_{\mathrm{A} 1}+\mathrm{A}_{2}-p_{\mathrm{B} 1}+\mathrm{B} 2+\mathrm{B} 3+{ }_{\mathrm{B} 4}\right|$.

c $d=\left|p_{\mathrm{A} 1}-p_{\mathrm{A} 2}\right|$.

${ }^{d} d=\left|p_{\mathrm{B} 4}-p_{\mathrm{B} 1}+\mathrm{B} 2+\mathrm{B}_{3}\right|$.

" $d=\left|p_{\mathrm{B} 3}-p_{\mathrm{B} 1}+{ }_{\mathrm{B} 2}\right|$.

${ }^{f} d=\left|p_{\mathrm{B} 1}-p_{\mathrm{B} 2}\right|$. 
TABLE 7. Average similarity of 12 test strains representing conventional species ${ }^{a}$

\begin{tabular}{lcccccccc}
\hline \multicolumn{1}{c}{ Test strain } & A1 & A2 & A3 & B1 & B2 & B3 & B4 & B5 \\
\hline Bacillus licheniformis CIP 5271 & $\underline{77.9}$ & 65.4 & 64.3 & 59.3 & 62.3 & 60.5 & 56.1 & 57.4 \\
B. subtilis CIP 5265 & 74.8 & 68.3 & 65.3 & 60.7 & 60.5 & 61.9 & 60.5 & 59.8 \\
B. pumilus CIP 5267 & 74.5 & $\underline{81.5}$ & 65.2 & 66.4 & 62.2 & 65.1 & 65.7 & 61.1 \\
B. cereus CIP A30 & 71.2 & 66.3 & $\underline{70.5}$ & 67.7 & 71.0 & 67.1 & 64.5 & 63.3 \\
B. cereus var. mycoides CIP 5269 & 71.0 & 64.4 & $\mathbf{6 5 . 0}$ & 61.9 & 64.9 & 59.4 & 60.4 & 57.0 \\
B. anthracis CIP A3 & 63.5 & 64.7 & 69.8 & 67.9 & 71.1 & 64.7 & 67.5 & 66.1 \\
B. megaterium CIP 5117 & 65.8 & 66.8 & 70.3 & 66.2 & 67.8 & 67.1 & 60.7 & 64.3 \\
B. firmus CIP 5269 & 61.0 & 66.0 & 68.1 & $\underline{74.6}$ & $\underline{74.9}$ & 67.6 & $\underline{75.6}$ & $\underline{70.0}$ \\
B. brevis CIP 5122 & 53.7 & 58.8 & 62.7 & 66.7 & 64.8 & 64.7 & 74.1 & 64.6 \\
B. pantothenticus CIP 5124 & 62.1 & 63.4 & 65.8 & 66.9 & 66.9 & 64.4 & 68.4 & 63.4 \\
B. sphaericus CIP 5125 & 52.1 & 64.1 & 61.8 & 66.9 & 60.5 & $\underline{70.0}$ & 68.1 & 65.9 \\
B. coagulans CIP 5263 & 61.0 & 62.0 & 63.7 & 62.4 & 57.4 & 60.2 & 62.4 & 61.9 \\
\hline
\end{tabular}

${ }^{a}$ Highest figure in columns is underlined.

TABLE 8. Occurrence among the $84 \mathrm{VP}$ - strains of the eight possible combinations of results to three tests distinguishing $B$. firmus (-- ) and B. megaterium $(+++)$

\begin{tabular}{|c|c|c|c|c|}
\hline \multirow[b]{2}{*}{ Width $>0.9 \mu \mathrm{m}$} & \multirow[b]{2}{*}{ Lipid droplets } & \multirow[b]{2}{*}{ Growth at pH 5.7} & \multicolumn{2}{|c|}{ No. of strains } \\
\hline & & & Observed & $\begin{array}{l}\text { Expected under null hypothe- } \\
\text { sis }\end{array}$ \\
\hline- & - & - & 10 & 14.4 \\
\hline- & - & + & 10 & 8.0 \\
\hline- & + & - & 25 & 18.4 \\
\hline - & + & + & 6 & 10.2 \\
\hline+ & - & - & 10 & 9.3 \\
\hline+ & - & + & 7 & 5.2 \\
\hline+ & + & - & 9 & 11.9 \\
\hline+ & + & + & 7 & 6.6 \\
\hline
\end{tabular}

A central strain of each phenon (Table 2, serial no. 13-22) was analyzed, and the individual SC and group averages to the VUB strains were computed. The results (not shown in detail) can be summarized as follows. The two strains representing phenons IIAT and IIIB (IHA 448 and IHA 321) had very low similarity to any of our strains or groups; the strains representing the remaining eight phenons developed high similarities with our phenons A1 or A2, or both, to the exclusion of all other groups. Though these results did little to clarify the relations, they were at least consistent with the observation that all of Bonde's 10 test strains in our hands were VP+, and this again emphasizes the importance of the Voges-Proskauer reaction.

\section{Gradient of Positivity}

Inspection of the data in Table 6 shows that, on the average, the strains of phenon $\mathrm{A} 1$ scored more positive results than those of A2, and the strains of cluster A scored more positive results than those of cluster B. This apparent trend was measured more precisely by computing for each strain the total of positive answers to the 43 tests (see Materials and Methods) which ex- pressed positive physiological or biochemical abilities (synthesis of a product, use of a substrate, ability to grow vigorously or in adverse conditions). The results are shown in Fig. 2. The proportion of positive results varied from over $80 \%$ for some strains of phenon A1 to less than $20 \%$ for some strains in the B3-B5 area. Not surprisingly, the lowest proportions were scored by nonfermenting strains.

The results establish the existence of a gradient of "positivity" when the strains are ordered according to the dendrogram.

\section{DISCUSSION}

Bacillus strains tend to exhibit "a graduated series of differences like the gradations of a spectrum in which colors fade into one another in sequence" (13). In addition, "all too often, the determination of a strain is impossible either because the currently accepted species are too poorly defined or because the distance to these species is excessive" (3). This state of affairs calls for the creation of more hospitable taxa. If these are to be defined by the method of numerical taxonomy, it is, however, essential that (i) a highly diversified and balanced set of nonredundant tests be used, and (ii) the strains un- 


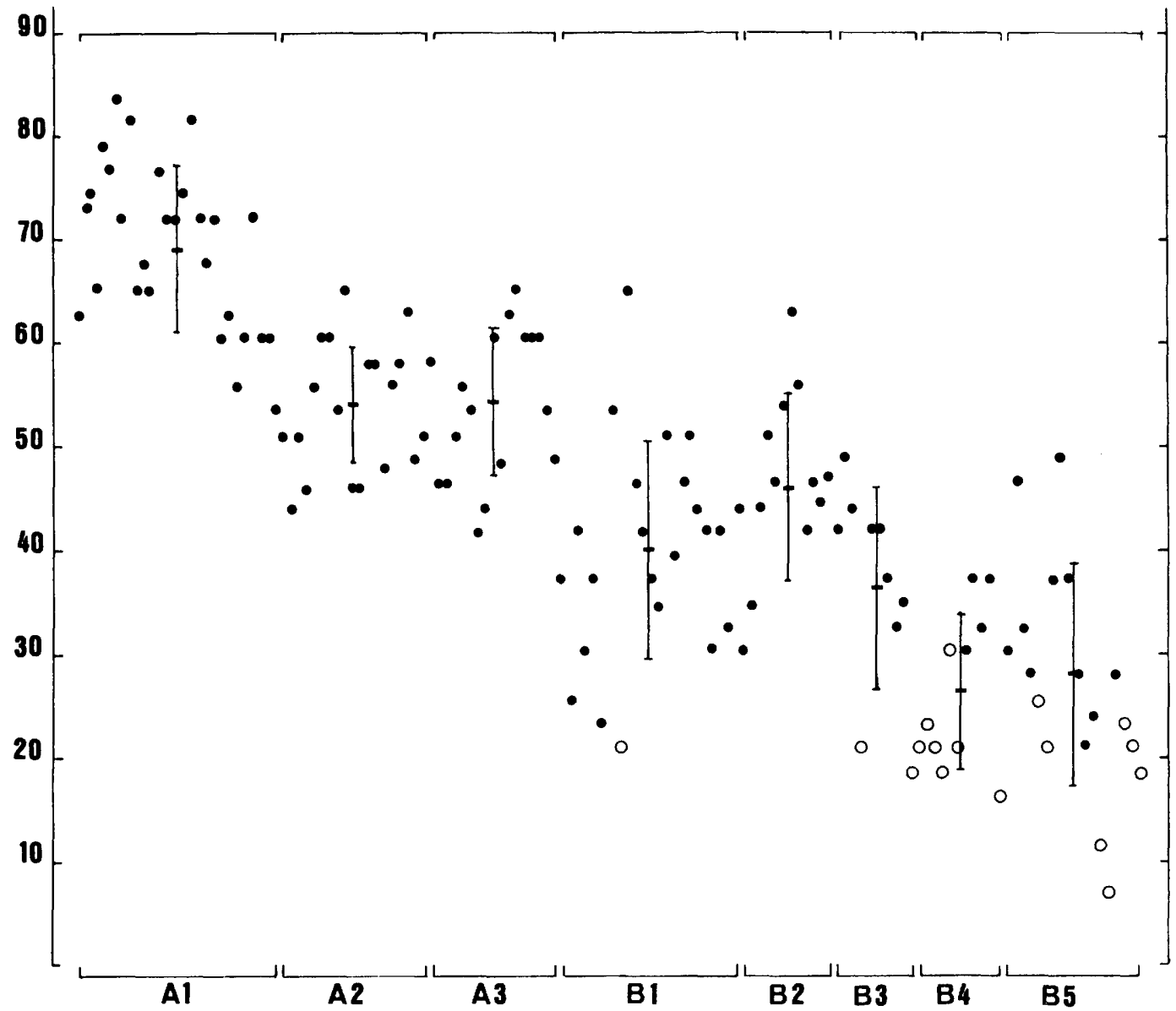

FIG. 2. Positivity index of individual strains and groups. Individual strains and groups (brackets) are ordered as in the dendrogram (Fig. 1). (Ordinate) Percent of positive results of 43 tests denoting positive physiological and biochemical abilities; (filled circles) glucid-fermenting strains; (open circles) nonfermenting strains; (bars and flags) group averages \pm standard deviation.

der investigation be drawn (preferentially at random) from natural habitats and certainly not from collections of named strains.

The present study of 138 random isolates from marine sediments satisfies these criteria. Two clusters, A and B, emerged, which differed by many features and most sharply by the Voges-Proskauer test. Except for a few marginal elements, all strains of cluster A were $\mathrm{VP}+$ and all strains of B were VP-. In our hands, the Voges-Proskauer test was perfectly reproducible, provided due allowance was made for slow acetoin producers.

Cluster A contained two tight phenons, one of which corresponded to the conventional species $B$. licheniformis. A few strains of cluster A were found to belong to five other species. Cluster B contained only a few identifiable strains, all of which were $B$. firmus.
All the species that turned up belonged to group I of Smith et al. (18); since nearly all the unidentified strains also had oval, nonbulging spores, they also belonged to that group.

To our knowledge, the only other available data on the Bacillus population of marine sediments are these of Bonde $(5,6)$. This investigator also found that a large proportion of the strains isolated from marine and coastal sediments belonged to the subtilis spectrum. Bonde reported species we did not encounter (Bacillus brevis, B. sphaericus, Bacillus pantothenticus) and failed to report $B$. firmus, but these discrepancies may be due to differences in methodology. Bonde probably used less stringent identification criteria since he considered only $16 \%$ of his isolates from marine and coastal muds unidentifiable, whereas the proportion of unidentified strains in our hands was $73 \%$. 
TABLE 9. Comparison of groups described in this paper and by Bonde (5)

\begin{tabular}{lcccc}
\hline & \multicolumn{3}{c}{ \% of strains possessing 10 critical features } \\
\cline { 2 - 5 } \multicolumn{1}{c}{ Characteristic } & $\begin{array}{c}\text { Cluster A } \\
\text { (this paper) }\end{array}$ & $\begin{array}{c}\text { Phenon IIIA } \\
\text { (Bonde) }\end{array}$ & $\begin{array}{c}\text { Cluster B } \\
\text { (this paper) }\end{array}$ & $\begin{array}{c}\text { Phenon IIB } \\
\text { (Bonde) }\end{array}$ \\
\cline { 2 - 5 } & $63^{a}$ & 43 & 74 & 24 \\
\hline Chains formed & 59 & 26 & 81 & 75 \\
Cell width >0.9 $\mu \mathrm{m}$ & 16 & 54 & 36 & 96 \\
Pellicle formed & 70 & 51 & 0 & 4 \\
Nonmotile (phase-contrast observation) & 5 & 9 & 64 & 8 \\
Lipid droplets present & 27 & 9 & 53 & 42 \\
VP+ (Clark-Lubs) & 84 & 98 & 1 & 8 \\
Nitrate reduced & 79 & 98 & 47 & 67 \\
Starch hydrolyzed & 65 & 86 & 45 & 79 \\
Pectate hydrolyzed & 79 & 71 & 9 & 33 \\
Anaerobic acid production (Hugh-Leifson) & 52 & 88 & 1 & 33 \\
\hline
\end{tabular}

${ }^{a}$ Number of strains.

In his study of mesophilic Bacillus isolates of different origins, Bonde $(5,6)$ obtained 10 phenons, most of which were unrelated to conventional species. Our own phenons or larger clusters could not be directly equated to any of these and the comparison was hampered by the different set of tests that were used. Still, a comparison based on 10 critical tests which were apparently performed in the same way in the two laboratories revealed the general statistical resemblance between our clusters $A$ and $\mathrm{B}$, and Bonde's phenons IIIA and IIB, respectively (Table 9 ).

Geslin (Ph.D. thesis, University of Poitiers, Poitiers, France, 1975) examined nearly $300 \mathrm{Ba}$ cillus strains from different aquatic biotopes and found that the predominant physiological groups were A1b (gelatin liquefied, nitrite produced, glucose fermented, lactose not fermented) and B1b (nitrite not produced, otherwise as A1b), in that order. Our own isolates exhibited the same pattern: 45 strains belonged to group $\mathrm{A} 1 \mathrm{~b}, 23$ belonged to $\mathrm{B} 1 \mathrm{~b}$, and no more than five belonged to any other single group. The correlation between those physiological groups and our own phenons was poor, however.

From the relative morphological homogeneity and the many invariant physiological characters of our new isolates, it may be concluded that the aerobic, sporulating rods one finds in North Sea sediments belong to a relatively small area of the Bacillus spectrum.

On the other hand, our isolates differed widely by the extent of their biochemical abilities. As shown in Fig. 2, a gradient of positivity (as measured by the proportion of positive answers to 43 physiological and biochemical tests) could be superimposed upon the dendrogram. Our findings can be compared to those of Joly
(Ph.D. thesis, University of Clermond-Ferrand, France, 1973) who established a "theoretical average profile" of 22 Bacillus species based on the final results of 83 biochemical tests and the time required for those results to become positive. Disregarding the time factor, we used Joly's data to compute the percentage of positive tests for the species relevant to the present work. The score of $B$. licheniformis (55\% positive) was roughly double that of $B$. firmus $(27 \%)$. Similarly, the positivity index of $69 \%$ obtained in the present work for phenon A1 (Fig. 2), which corresponded to $B$. lichenifor$m i s$, was about double that of cluster B $(35 \%)$ which was related to $B$. firmus. Both Joly's and our own findings suggest that Bacillus taxa, whether conventional or numerical, may be ranked by an index of positivity. This index may perhaps turn out to be the unifying concept or "wavelength" of the Bacillus spectrum.

Looking to our data from another perspective, the coexistence in the same biotope of strains with very different biochemical capabilities also raises an intriguing ecological problem.

\section{ACKNOWLEDGMENTS}

This work was part of a national program on the physical and biological environment, carried out under contract no. M12 of the Interdepartmental Committee for Scientific Programmation, Belgium.

We thank T. D'Hondt for his invaluable help with computer programs and D. Van Oudheusden for permission to use one of his own programs, G. J. Bonde and J. Wolf for providing test strains, and last but not least Greta Clerx for her excellent technical assistance.

\section{REPRINT REQUESTS}

Address reprint requests to: Dr. A. Boeyé, Laboratory of Microbiology and Hygiene, Vrije Universiteit Brussel, 1640 St. Genesius-Rode, Belgium. 


\section{LITERATURE CITED}

1. Baird-Parker, A. C. 1966. Methods for classifying staphylococci and micrococci, p. 59-64. In B. M. Gibbs and F. A. Skinner (ed.), Identification methods for microbiologists, part A. Academic Press Inc., London.

2. Baker, F. J. 1967. Handbook of bacteriological technique, 2nd ed. Butterworths, London.

3. Barjac, H. de, and V. Cosmao-Dumanoir. 1975. Intérêt de certains critères biochimiques supplémentaires pour la classification des souches de Bacillus. Ann. Microbiol. (Paris) 126A:83-95.

4. Boeyé, A., M. Wayenbergh, and M. Aerts. 1975. Density and composition of heterotrophic bacterial populations in North Sea sediments. Mar. Biol. 32:263270.

5. Bonde, G. J. 1973. The genus Bacillus. ISS Research Council, series 2, Copenhagen.

6. Bonde, G. J. 1975. The genus Bacillus. Dan. Med. Bull. 22:41-61.

7. Breuil, C., and A. M. Gounot. 1972. Recherches préliminaires sur les bactéries lipolytiques psychrophiles des sols et des eaux. Can. J. Microbiol. 18:1445-1451.

8. Brisou, J. 1971. Techniques d'enzymologie bactérienne. Masson, Paris.

9. Burdon, K. L. 1946. Fatty material in bacteria and fungi revealed by staining dried, fixed slide preparations. J. Bacteriol. 52:665-678.

10. Buttiaux, R., H. Beerens, and H. Tacquet. 1969. Manuel de techniques bactériologiques, 3rd ed. Flammarion, Paris.

11. Delaporte, B. 1964 . Etude descriptive de bactéries de très grandes dimensions. Ann. Inst. Pasteur Paris 107:845-862.

12. Gordon, R. E. 1973. The genus Bacillus, p. 71-88. In A. I. Laskin and H. A. Lechevalier (ed.), Handbook of microbiology, vol. 1. CRC Press, Cleveland.

13. Gordon, R. E., W. C. Haynes, and C. N-H. Pang. 1973. The genus Bacillus, p. 2. U.S. Department of Agriculture Handbook no. 427, Washington, D.C.
14. Hankin, L., M. Zucker, and D. C. Sands. 1971. Improved solid medium for the detection and enumeration of pectolytic bacteria. Appl. Microbiol. 22:205209.

15. Holding, A. J., and J. G. Collee. 1971. Routine biochemical tests, p. 1-32. In J. R. Norris and D. W. Ribbons (ed.), Methods in microbiology, vol. 6A. Academic Press Inc., London.

16. Oxoid Ltd. 1971. The Oxoid manual of culture media, ingredients and other laboratory services, 3rd ed. Oxoid Ltd., London.

17. Prévot, A. R. 1961. Traité de systématique bactérienne, vol. 2, p. 335. Dunod, Paris.

18. Smith, N. R., R. E. Gordon, and F. E. Clark. 1946. Aerobic mesophilic sporeforming bacteria. U.S. Department of Agriculture Miscellaneous Publication no. 559, Washington, D.C.

19. Sneath, P. H. A., and R. R. Sokal. 1973. Numerical taxonomy, p. 230-234. Freeman, San Francisco.

20. Society of American Bacteriologists (ed.). 1957. Manual of microbiological methods. McGraw-Hill, New York.

21. Walc-Porkzywnicki, Z. 1973. Flagella staining. Zentralbl. Bakteriol. Parasitenkd. Infektionskr. Hyg. Abt. 1 Orig. Reihe A 223:240-243.

22. Walker, P. D., and J. Wolf. 1971. The taxonomy of Bacillus stearothermophilus, p. 247-262. In A. N. Barker, G. W. Gould, and J. Wolf (ed.), Spore research 1971. Academic Press Inc., London.

23. Williams, S. T., and T. Cross. 1971. Actinomycetes, p. 295-334. In C. Booth (ed.), Methods in microbiology, vol. 4. Academic Press Inc., London.

24. Wolf, J., and A. N. Barker. 1968. The genus Bacillus: aids to the identification of its species, p. 93-109. In B. M. Gibbs and D. A. Shapton (ed.), Identification methods for microbiologists, part B. Academic Press Inc., London.

25. ZoBell, C. E. 1941. Studies on marine bacteria. I. The cultural requirements of heterotrophic aerobes. J. Mar. Res. 4:42-76. 